\title{
A EDUCAÇÃO CATÓLICA PASSIONISTA EM TEMPOS DE RENOVAÇÃO EDUCACIONAL: TRAÇOS DOS SABERES ELEMENTARES DA MATEMÁTICA NOS LIVROS DE LEITURA (1927 - 1933)
}

\section{CATHOLIC PASSIONISTA EDUCATION IN TIMES OF EDUCATIONAL RENEWAL: THE BASIC MATH READING BOOKS TRACES OF KNOWLEDGE $(1927$ - 1933)}

\author{
ORLANDO, Evelyn \\ evelynorlando@gmail.com \\ PUCPR - Pontifícia Universidade Católica do Paraná \\ MOTIN, Mara \\ maramotin@hotmail.com \\ PUCPR - Pontifícia Universidade Católica do Paraná
}

\begin{abstract}
RESUMO O artigo tem como estudo a atuação das Irmãs Passionistas, entre os anos de 1927 e 1933, no Colégio Santo Antonio, em Colombo/PR. Objetiva-se demarcar uma aproximação entre a educação católica e a renovação educacional, em tempos de Escola Nova (MAGALDI, 2007; ORLANDO, 2008), compreendendo a influência pedagógica na escola e os modos como os saberes elementares da Matemática apareceram nos materiais didáticos. Metodologicamente este trabalho está ancorado no paradigma indiciário (GINZBURG, 1989), utilizando como fontes documentos da Congregação e da Igreja, jornais e livros de leitura. Neste conjunto, destaca-se uma influência paulista, refletindo na Matemática as discussões do período, tendo esta um aspecto prático para a formação de um cidadão nacional.

Palavras-chave: Educação Católica. Renovação Educacional. Saberes Elementares da Matemática.
\end{abstract}

SUMMARY This article aims to study the performance of the Passionist Sisters, between the years 1927 and 1933, in Santo Antonio Elementary School in Colombo/PR. The purpose of this work is to demarcate a rapprochement between the Catholic education and educational renewal in times of New School (MAGALDI, 2007; ORLANDO, 2008), comprising the pedagogical influence in school and the ways in which basic knowledge of mathematics appeared in textbooks. Methodologically this work is anchored on evidential paradigm (GINZBURG, 1989), using as source documents of the Congregation and the Church, newspapers and books. In this set, a regional influence of São Paulo State speech stands out, reflecting in Mathematics the debates of the period which had a practical aspect to the formation of a national citizen.

Keywords: Catholic Education. Educational Renewal. Elementary Knowledge of Mathematics.

\section{INTRODUÇÃO}




\title{
Atos de Pesquisa em Educação - ISSN 1809-0354 \\ Blumenau, v. 12, n.2, p.302-323, mai./ago. 2017 \\ DOI: http://dx.doi.org/10.7867/1809-0354.2017v12n2p302-323
}

A nova fase que o período republicano trouxe ao Brasil foi marcada por uma reestruturação do plano político, que inevitavelmente envolveu variáveis educacionais. Nesse contexto, uma das principais mudanças foi o afastamento oficial entre o Estado e a Igreja Católica, impulsionando esta última instituição a criar novas estratégias para a manutenção do seu campo de influência. Além da defesa de um estado não laico,

\begin{abstract}
Nesse momento, a Educação Católica passa a ser elemento de destaque na estratégia do Episcopado para acelerar o processo de romanização da Igreja no Brasil, e para fazer face à rede de escolas protestantes que começam a surgir, um pouco por toda a parte, no território nacional. É justamente neste período, [...] que são fundados no Brasil, ou aqui vêm se instalar, muitas Congregações Religiosas, especialmente as dedicadas à educação escolar da juventude, tanto masculina, quanto feminina. (ALVES, 2005, p. 210)
\end{abstract}

Durante essa reestruturação educacional e busca de espaços pela Igreja Católica, chegaram ao Brasil, em 1919, as Irmãs Passionistas para assumir, em São Paulo, um abrigo para menores. Esse período, marcado por muitas discussões educacionais, o qual teve início no fim do século XIX, quando pelo "[...] projeto liberal dos republicanos paulistas, a educação tornou-se uma estratégia de luta, um campo de ação política, um instrumento de interpretação da sociedade brasileira e o enunciado de um projeto social" (SOUZA, 1998, p. 26).

Mesmo a escola tendo sido um campo privilegiado no projeto republicano paulista para o ordenamento da população brasileira, como também da Igreja, para manutenção da sua influência, as Irmãs Passionistas não adentram neste país para assumir ou fundar escolas oficiais. Entretanto, apreende-se em uma publicação no jornal O Estado de São Paulo, a preocupação com a instrução dos sujeitos atendidos no abrigo e uma intenção anunciada, que dependia apenas do domínio da língua portuguesa, para ser posta em prática.

Soubemos ainda que as asyladas estão crescendo sem instrucção, por falta de uma escola, e que ha promessa de se criar uma de primeiras letras, quando qualquer das tres irmans de caridade chegar a conhecer a nossa língua e puder leccionar. (O ESTADO DE SÃO PAULO, 1920, p. 5) 


\title{
Atos de Pesquisa em Educação - ISSN 1809-0354 \\ Blumenau, v. 12, n.2, p.302-323, mai./ago. 2017 \\ DOI: http://dx.doi.org/10.7867/1809-0354.2017v12n2p302-323
}

Tal projeto se concretizou quatro anos depois da chegada ao Brasil, no dia 3 de julho de 1923, por meio de um despacho favorável para abertura de uma escola particular, atendendo alunos externos (PASSIONISTAS, [s.d.]). Com sua primeira instituição particular de ensino, no Estado de São Paulo, essas religiosas tiveram referências importantes, uma vez que,

\begin{abstract}
A atuação dos reformadores paulistas nos anos iniciais do novo regime permitiu que se consolidasse uma estrutura quase que intacta em suas linhas essenciais nos primeiros 30 anos da República e que seria apresentada como paradigma aos demais estados, muitos dos quais reorganizaram seus sistemas a partir do modelo paulista [...]. (TANURI, 2000, p. 68)
\end{abstract}

Impregnadas de um referencial educacional paulista, as Irmãs assumiram a coordenação de novas instituições de ensino em outros estados brasileiros. A expansão foi iniciada na cidade de Curitiba. Primeiro, assumiram um asilo, voltado mais para uma atuação social. E, em 1927, as Passionistas foram convidadas a coordenar uma instituição de ensino, no município de Colombo, região metropolitana de Curitiba.

Em Colombo, as Irmãs assumiram o Colégio Santo Antonio, uma instituição idealizada por imigrantes italianos, que contribuíram na fundação dessa cidade. Essas religiosas ficaram a frente dessa instituição, em um primeiro momento, entre os anos de 1927 e 1933 - décadas marcadas pelas discussões educacionais e reestruturação desse campo, no âmbito nacional -, retornando, em 1951, e ali permanecem até os dias atuais.

Este artigo destaca o primeiro momento de atuação das Irmãs, no município de Colombo, e busca compreender traços da influência pedagógica seguida por essas religiosas, focando nos materiais didáticos solicitados pela escola e nos conteúdos que os mesmos privilegiaram para a circulação, dentre estes, os saberes elementares da Matemática. Busca-se demarcar uma aproximação entre a educação católica colombense e a renovação educacional, em tempos de Escola Nova, conforme já demonstrado em outras localidades, por Magaldi (2007) e Orlando (2008), mas que ainda traziam rudimentos do ensino intuitivo do início da República. 


\section{Atos de Pesquisa em Educação - ISSN 1809-0354 \\ Blumenau, v. 12, n.2, p.302-323, mai./ago. 2017 \\ DOI: http://dx.doi.org/10.7867/1809-0354.2017v12n2p302-323}

Para essa construção, utilizam-se como fontes jornais da época, documentos da Congregação e da Igreja e livros de leitura da Coleção Proença e da Série Braga. O caminho metodológico desse trabalho está ancorado no paradigma indiciário, tal como proposto por Ginzburg (1989), uma vez que as fontes foram produzidas a partir de pistas deixadas pelas Irmãs como rastros de sua trajetória, muitas vezes sombreados e obscurecidos pela poeira dos arquivos e dos documentos.

\section{CARACTERIZANDO AS IRMÃS PASSIONISTAS EM COLOMBO}

A história do Colégio Santo Antonio, em Colombo, possui cinco momentos, apresentando mudanças entre coordenação e mantenedoras, conforme se apreende na tabela 1:

Tabela 1: Momentos da instituição escolar em Colombo/PR

\begin{tabular}{|c|c|c|c|}
\hline Nome da Escola & Coordenação & Subsídios & Período \\
\hline Scuola Santo Antonio & $\begin{array}{l}\text { Società Italiana Cristoforo } \\
\text { Colombo }\end{array}$ & Italiano & $\begin{array}{l}\text { Décadas de } 1900 \text { e } \\
1910\end{array}$ \\
\hline $\begin{array}{l}\text { Colégio } \\
\text { Antonio }\end{array}$ & $\begin{array}{l}\text { Irmãs Zeladoras do Sagrado } \\
\text { Coração de Jesus } \\
\text { (congregação italiana) }\end{array}$ & Italiano & Entre 1917 e 1927 \\
\hline $\begin{array}{l}\text { Colégio } \\
\text { Antonio }\end{array}$ & $\begin{array}{lcc}\text { Irmãs } & \text { Passionistas de } & \text { São } \\
\text { Paulo da } & \text { Cruz } \\
\text { (congregação italiana) } & \\
\end{array}$ & Brasileiro & Entre 1927 e 1933 \\
\hline $\begin{array}{l}\text { Colégio } \\
\text { Antonio }\end{array}$ & $\begin{array}{l}\text { Irmãs de São José de } \\
\text { Chambéry } \\
\text { francesa) }\end{array}$ & & Entre 1935 e 1948 \\
\hline $\begin{array}{l}\text { Educandário Nossa } \\
\text { Senhora do Rosário }\end{array}$ & $\begin{array}{lcc}\text { Irmãs } & \text { Passionistas de } & \text { São } \\
\text { Paulo da } & \text { Cruz } \\
\text { (congregação italiana) } & \\
\end{array}$ & $\begin{array}{l}\text { Brasileiro (nas } \\
\text { primeiras décadas } \\
\text { do retorno) }\end{array}$ & $\begin{array}{l}\text { De } 1951 \text { até os dias } \\
\text { de hoje }\end{array}$ \\
\hline
\end{tabular}

Fonte: Livro Tombo (1900); Passionistas (1951); Maschio (2012).

Antes das Passionistas assumirem o Colégio Santo Antonio, o mesmo foi caracterizado como uma Regia Scuola Italiana, ou seja, uma escola subsidiada pelo governo italiano, e mantida no município de Colombo pela Società Italiana Cristoforo Colombo. Inicialmente, esta instituição atendia apenas os meninos, filhos dos associados, com aulas em italiano.

No ano de 1917, a antiga Scuola Santo Antonio foi ampliada e reformulada, tendo sua abertura oficial no dia 22 de julho, quando passou a se chamar Colégio Santo Antonio, atendendo tanto meninos, como meninas. Nesta nova fase, o Colégio 


\section{Atos de Pesquisa em Educação - ISSN 1809-0354 \\ Blumenau, v. 12, n.2, p.302-323, mai./ago. 2017 \\ DOI: http://dx.doi.org/10.7867/1809-0354.2017v12n2p302-323}

ganhava conotações católicas, com coordenação da congregação feminina das Irmãs Zeladoras do Sagrado Coração de Jesus.

Mesmo com a ampliação e mudança de coordenação, a instituição manteve o ensino em língua italiana, com as Irmãs do Sagrado Coração, conforme apontam os trabalhos de Maschio (2012) e Zoca (2007). Pode-se inferir tal afirmativa pelo fato das professoras do Colégio serem de origem italiana. Todavia, em 1926, respondendo a uma questão dos "Mappas Escolares"1 , sobre a existência de alguma instituição particular de ensino próxima à escola pública e sobre a língua adotada nessa instituição, o professor Manoel Gonçalves Padilha, professor da Escola Pública de Colombo, colocou que existia uma escola particular, próxima a sua, se referindo ao Colégio Santo Antonio, e que a mesma era dirigida por cinco irmãs de nacionalidade italiana, porém, deixou evidente que as mesmas falavam o português e ensinavam essa matéria (PARANÁ, 1926). Tal mudança é sintomática do processo de nacionalização que se instaurou no Brasil, nos anos de 1920, e que se estendeu a todas as instituições de ensino, públicas e privadas, tornando a educação uma das principais ferramentas do nacionalismo, sobretudo pela afirmação da língua portuguesa como um dos símbolos da identidade nacional.

A partir deste período, outro cenário de nação foi se desenhando e novos debates educacionais se instauraram no sentido de buscar a pedagogia mais eficaz para a formação do novo cidadão. O "otimismo pedagógico", tal como se referiu Jorge Nagle (1974), atribuiu à educação a missão de remodelar a sociedade pela produção do novo cidadão e fez do cenário educacional, um espaço de disputas políticas com frentes defendidas por grupos distintos, que apresentavam propostas pedagógicas coerentes com seus ideais de formação da nação. Fossem com foco privilegiado no crescimento econômico do Brasil, religioso e/ou cultural, os grupos que estavam em voga "apresentavam projetos de remodelação da sociedade em face das novas necessidades da vida moderna, que exigiam da educação um novo tipo de sujeito a ser formado" (ORLANDO, 2008, p.175).

É nesse contexto de efervescência educacional no Brasil, que as Irmãs Passionistas chegam para assumir o Colégio Santo Antonio, em Colombo, no ano de 1927. A chegada destas religiosas trouxe uma mudança significativa para a

\footnotetext{
${ }^{1}$ Tipo de relatório que o Estado do Paraná exigia dos estabelecimentos de ensino.
} 


\section{Atos de Pesquisa em Educação - ISSN 1809-0354 \\ Blumenau, v. 12, n.2, p.302-323, mai./ago. 2017 DOI: http://dx.doi.org/10.7867/1809-0354.2017v12n2p302-323}

instituição, destacando que, mesmo sendo de uma congregação católica italiana, as freiras não eram de origem italiana e o Colégio, que anteriormente recebeu subsídios do governo italiano, nessa nova fase, com as Passionistas, passou a contar apenas com subsídios do governo brasileiro. Outro detalhe importante é que não se encontraram indícios do ensino em italiano, sendo as aulas somente em língua portuguesa. Dessa forma, com um primórdio apoiado na nacionalidade italiana, nessa nova fase, no final da década de 1920, as Passionistas, recebendo subsídios públicos nacionais e possivelmente visando manter este apoio financeiro, ou por outros motivos, passam a ter o compromisso do uso da língua portuguesa, em meio aos debates de formação de um cidadão nacional.

A partir das Atas da Congregação e Relatórios de Governo, fez-se o levantamento dos possíveis nomes das religiosas que estiveram em Colombo, entre 1927 e 1933 (PASSIONISTAS, s.d; PARANÁ, 1928; PARANÁ, 1929; PARANÁ, 1930a; PARANÁ, 1931). Com base no registro de entrada das vocações na Congregação Passionista, tem-se as seguintes informações:

Tabela 2 - Religiosas Passionistas que atuaram em Colombo (1927 - 1933)

\begin{tabular}{|c|c|c|c|c|c|c|}
\hline $\mathrm{N}^{0}$ & Nome & Filiação & $\begin{array}{l}\text { Lugar de } \\
\text { nascimento }\end{array}$ & $\begin{array}{l}\text { Data de } \\
\text { nascimento }\end{array}$ & Entrada & Obs. \\
\hline 8 & $\begin{array}{l}\text { Irmã Rafaela da } \\
\text { Agonia de Jesus } \\
\text { Anna Bento }\end{array}$ & $\begin{array}{l}\text { Manoel Bento } \\
\text { Justina }\end{array}$ & 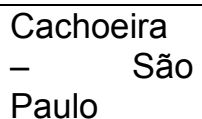 & 26-8-1902 & $6-10-1921$ & $\begin{array}{l}\text { Saiu a 5-4- } \\
1939\end{array}$ \\
\hline 10 & $\begin{array}{l}\text { Irmã Tereza da } \\
\text { Coroação } \\
\text { Mariana Maria } \\
\text { de Paula }\end{array}$ & $\begin{array}{l}\text { Manoel de } \\
\text { Paula } \\
\text { Maria Faustina } \\
\text { de Paula }\end{array}$ & $\begin{array}{lr}\text { São } & \text { Paulo } \\
- & \text { São } \\
\text { Paulo } & \end{array}$ & $22-10-1893$ & $14-7-1922$ & $\begin{array}{l}\text { Falecida 28-4- } \\
1957\end{array}$ \\
\hline 20 & $\begin{array}{l}\text { Irmã Faustina do } \\
\text { Menino Jesus } \\
\text { Otília Cândida F. } \\
\text { dos Reis }\end{array}$ & $\begin{array}{l}\text { José dos Reis } \\
\text { Marcelina de } \\
\text { Jesus }\end{array}$ & $\begin{array}{l}\text { Paradinha } \\
\text { Outeiro - } \\
\text { Portugal }\end{array}$ & 4-4-1907 & 25-3-1925 & $\begin{array}{l}\text { Falecida 25-9- } \\
1975\end{array}$ \\
\hline 23 & $\begin{array}{l}\text { Irmã Vicentina } \\
\text { de N. Senhora } \\
\text { Yolanda Sasso }\end{array}$ & José Sasso & $\begin{array}{lr}\text { São } & \text { Paulo } \\
- & \text { São } \\
\text { Paulo } & \\
\end{array}$ & & $22-7-1926$ & $\begin{array}{l}\text { Saiu a 2-4- } \\
1934\end{array}$ \\
\hline
\end{tabular}

Fonte: PASSIONISTAS, 1920.

Sobre as Irmãs, poucas informações foram recuperadas, além dos dados de entrada das mesmas na Congregação. A partir dessa tabela, uma característica que é ressaltada, é o fato de três, das quatro freiras que estiveram em Colombo, serem naturais do Estado de São Paulo. Cabe denotar também que a formação dessas freiras se dava naquele Estado, uma vez que o convento das mesmas estava 


\section{Atos de Pesquisa em Educação - ISSN 1809-0354 \\ Blumenau, v. 12, n.2, p.302-323, mai./ago. 2017 \\ DOI: http://dx.doi.org/10.7867/1809-0354.2017v12n2p302-323}

localizado no bairro Pinheiros, como ocorreu com Irmã Faustina, que era portuguesa ${ }^{2}$.

Essas relações entre as religiosas professoras do Colégio com o Estado de São Paulo, pela sua formação religiosa e acadêmica que tiveram naquele Estado permite inferir que o modelo escolar paulista inspirou o ideário pedagógico do Colégio Santo Antonio. Segundo Giznburg (1989, p. 152),

O que caracteriza esse saber é a capacidade de, a partir de dados aparentemente negligenciáveis, remontar a uma realidade complexa não experimentável diretamente. Pode-se acrescentar que esses dados são sempre dispostos pelo observador de modo tal a dar lugar a uma sequência narrativa, cuja formulação mais simples poderia ser "alguém passou por lá".

Outra influência forte se dá pelo fato de que, nos anos de 1920, "a escola paulista é estrategicamente erigida como signo do progresso que a República instaurava" (CARVALHO, 2011, p. 225), o que ressonava em outros estados, como o Paraná, que já tinha uma tradição em seguir os preceitos paulistas, oriunda pelo fato de ter feito parte da Província desse Estado até 1853. Cabe ressaltar que desde o final do século XIX, esta discussão de um novo cidadão já era posta pela divulgação do Método Intuitivo, que visava

[...] tornar a criança o centro de sua própria aprendizagem, levando até ela os objetos da natureza para serem observadas, estava em consonância com as idéias difundidas pelo novo tipo de governo que regeria a nação a partir daquele momento, a República. (RESENDE; SOUZA, 2005, p. 3)

A efervescência dos debates educacionais e da crença na educação como ferramenta de remodelação da sociedade acentuou as diferentes concepções sobre a educação escolar nas primeiras décadas do século $\mathrm{XX}$, o que acabou por colocar

\footnotetext{
${ }^{2}$ Sobre a Irmã Faustina, única estrangeira, encontrou-se uma matéria publicada no Diário do Paraná, em 28 de abril de 1972, intitulada "Religiosa é a primeira a usufruir tratado de igualdade", em comemoração a primeira cidadã portuguesa, ter tirado o título de eleitora. Nesse texto, apresentou-se uma breve biografia de Irmã Faustina, conforme o trecho retirado do mesmo: "Otília Frederique dos Reis, que ao ingressar na carreira religiosa recebeu o nome de Irmã Faustina, nasceu a quatro de abril de 1907, na Paradinha de Outeiro, Distrito de Bragança. Ainda jovem, mais exatamente em 1915, veio para o Brasil juntamente com sua família, indo residir em São Paulo, onde continuou seus estudos. Na capital paulista fez o colegial, prestou exames para professora particular do ensino primário. Aos 18 anos ingressava na carreira religiosa, no Educandário Santa Maria. Veio, pela primeira vez ao Paraná em 1927, tendo lecionado por algum tempo no município de Colombo, tendo regressado novamente para São Paulo" (DIÁRIO DO PARANÁ, 1972, s.p.).
} 


\section{Atos de Pesquisa em Educação - ISSN 1809-0354 \\ Blumenau, v. 12, n.2, p.302-323, mai./ago. 2017 \\ DOI: http://dx.doi.org/10.7867/1809-0354.2017v12n2p302-323}

o cenário educacional como um palco de disputas que foi se acirrando entre dois principais grupos, que se convencionou chamar de "pioneiros" e católicos ${ }^{3}$. Dentre os projetos em disputa, articulou-se um conflito entre os defensores da escola particular e os da escola pública.

Os primeiros, em geral agrupados em torno da Igreja Católica, defendiam uma concepção religiosa e humanista do ensino, e até reclamavam um financiamento público para a educação particular, de modo a garantir a "liberdade de escolha" dos pais. Os outros, em seus movimentos progressistas e laicos, previam que apenas uma escola pública haveria de assegurar as mesmas chances educativas para todos os cidadãos brasileiros. (SANTOS; PRESTES; VALE, 2006, p. 145)

Tal antagonismo se justifica pelo forte investimento que a Igreja fez na organização de uma rede de colégios confessionais, ao buscar recuperar o espaço que havia perdido oficialmente na educação ${ }^{4}$. Mesmo com divergências em alguns pontos, principalmente na questão do ensino laico, a renovação do campo educacional era uma necessidade entendida por ambos os grupos, os quais se fizeram presentes na $A B E$, ao longo de toda a década de 1920. Essa "presença de intelectuais católicos desde o início da fundação da Associação e a ausência de um antagonismo mais contundente entre os projetos revela a disputa de campo muito mais política que educacional" (ORLANDO, 2008, p. 165). No plano pedagógico, o antagonismo foi bem mais sutil. Assim, conforme coloca Magaldi (2007):

O fato de ressaltarmos a presença de focos de oposição entre os grupos que, inclusive, não devem ser compreendidos como dotados de um caráter homogêneo - não significa, no entanto, a adesão a uma corrente

\footnotetext{
${ }^{3} \mathrm{O}$ termo "pioneiros" é utilizado neste trabalho para referenciar o grupo que assinou o Manifesto da Educação Nova, em 1932, documento que representou um divisor de águas nessa disputa, pois resultou na saída dos intelectuais católicos da Associação Brasileira de Educação (ABE) que fundaram a Confederação Católica Brasileira de Educação (CCBE), como um espaço político próprio e representativo desse grupo. Ao usar o termo "grupo católico", nos referimos a esse como os educadores militantes, que encamparam a defesa da reorganização da sociedade em bases católicas e defenderam ampla e abertamente o projeto de recristianização da sociedade pela educação. Ambos os grupos, em que pesem suas divergências políticas, apresentavam pontos de aproximação e distanciamento em suas propostas pedagógicas e se envolveram com a renovação do campo educacional.

${ }^{4}$ A perda oficial do espaço que sempre ocupou na educação brasileira levou a Igreja Católica a desenvolver duas estratégias fundamentais em relação à escolarização da sociedade. De um lado, organizou uma rede de colégios confessionais voltados, sobretudo, para o ensino secundário; e, de outro, buscou a reintrodução do ensino religioso nas escolas públicas paralelamente a um investimento expressivo na formação de um professorado católico militante capaz de levar a religião para o interior da escola, instaurando-a como um símbolo de uma cultura impregnada de catolicidade.
} 


\title{
Atos de Pesquisa em Educação - ISSN 1809-0354 \\ Blumenau, v. 12, n.2, p.302-323, mai./ago. 2017 \\ DOI: http://dx.doi.org/10.7867/1809-0354.2017v12n2p302-323
}

interpretativa que define um grupo como renovador e o outro como conservador. (MAGALDI, 2007, p. 115)

A existência de pontos de convergência entre os dois grupos e a aderência dos católicos ao movimento de renovação educacional permite pensar que o movimento da Escola Nova no Brasil teve uma face católica. É importante ressaltar, conforme destaca Orlando (2008) que

\begin{abstract}
A adesão ao movimento não implica, necessariamente, na obediência a todos os pontos estabelecidos. Nem todas as escolas novas obedeceram aos trinta pontos referidos de modo integral, o que avaliza a apropriação como uma prática legítima dos diferentes grupos que compõem a sociedade em relação a determinada idéia ou objeto. (ORLANDO, 2008, p. 171)
\end{abstract}

Assim, de modos muito distintos, os grupos aderiram ao movimento e se apropriaram de seus enunciados, pois entenderam que suas propostas pedagógicas eram mais eficazes porque traziam as contribuições das ciências educacionais. A articulação com o projeto de renovação educacional significava para os católicos uma tática de reestruturação de seu campo de influência, no Brasil.

Para os católicos, portanto, seria fundamental que, estabelecendo contato com as novidades que circulavam no campo educacional, construíssem acerca das mesmas interpretações próprias, que deveriam ser disseminadas na sociedade, de forma a concorrer com vantagens diante dos defensores da educação laica. (MAGALDI, 2007, p. 121)

Em que pese, compreende-se que este processo de renovação educacional em tempos de Escola Nova, tem rudimentos nos esforços de divulgação do Ensino Intuitivo, no início da República. Carvalho (2000) traz que nas décadas de 1920 e 1930 têm-se nas discussões e nas propostas para a educação paulista as ideias do movimento da Escola Nova, concomitantemente às ideias do ensino intuitivo. Neste sentido, Resende e Souza (2005, p. 9) afirmam que "diante da necessidade de métodos e propostas novas, o método intuitivo foi sendo apropriado pelo escolanovismo que renegava as suas origens".

Buscando compreender a Congregação Passionista nesse cenário, percebese a defesa de uma educação católica, como modeladora do nacionalismo e da sociedade brasileira. Logo, imbuídas pelos debates em torno da renovação do 


\section{Atos de Pesquisa em Educação - ISSN 1809-0354 \\ Blumenau, v. 12, n.2, p.302-323, mai./ago. 2017 \\ DOI: http://dx.doi.org/10.7867/1809-0354.2017v12n2p302-323}

campo educacional, as Irmãs Passionistas solicitaram para uso no Colégio Santo Antonio materiais didáticos produzidos no Estado de São Paulo, impregnados desse repertório. Estes materiais traziam para a discussão diversos conteúdos, como Ciências, História e até mesmo os saberes elementares da Matemática, tendo como fio condutor na apresentação das lições o modelo de concepção que se visava implantar na formação dos novos cidadãos brasileiros.

\section{OS LIVROS DE LEITURA E A MATEMÁTICA}

Em um cenário marcado por debates e divergências de ideias, visando à estruturação nacional, pelo viés educacional, tem-se a expansão do mercado editorial brasileiro, na década de 1920, principalmente pelo caminho da produção de livros didáticos, em que muitos eram utilizados como modeladores e com uma clara mensagem na renovação educacional, "[...] que promotores do desenvolvimento da indústria editorial e agentes do movimento educacional vão conjugar suas ações em prol de uma mudança cultural do Brasil" (TOLEDO, 2001, p. 11). Dentre estes materiais, os didáticos associados à leitura ganharam grande espaço nas escolas, sendo muitas vezes um dos únicos livros utilizados em sala de aula, trazendo em seus textos, a abordagem de assuntos morais, cívicos e científicos.

Diante desse contexto e na ocorrência mais frequente no uso de livros nas escolas brasileiras, encontrou-se um ofício direcionado ao Diretor de Instrução Pública do Estado do Paraná, feito pela Irmã Faustina, solicitando livros de leitura para o Colégio Santo Antonio:

\footnotetext{
Dr. Director da Instrucção Publica

Eu abaixo assignada, professora da escola do Collegio $S{ }^{\text {to }}$ Antonio, em Villa Colombo, venho humildemente solicitar de $\mathrm{V}^{\mathrm{a}} \mathrm{S}^{\mathrm{a}} \|_{\mathrm{II}}^{\mathrm{ma}}$ o fornecimento de 15 Proença I. 15 livros para a $\|^{a}$ serie. 100 cadernos de linguagem, 100 cadernos de calligraphia, 100 calculos. 1 armario pequeno. 1 quadro negro. 2 apagadores, 50 canetas, 3 tinteiros para professora, 15 Proença $\mathrm{III}^{\circ}$ anno, 10 Erasmos ${ }^{\circ}{ }^{\circ}$ ano e 3 História do Paraná.

Pelo que, antecipadamente agradeço

Faustina Frederique

Colombo, 23 de Agosto de 1930. (PARANÁ, 1930b)
}

Dentre os materiais solicitados, destacam-se os livros de leitura da Coleção Proença e da Série Braga. Ambas as coleções foram escritas por autores que 


\section{Atos de Pesquisa em Educação - ISSN 1809-0354 \\ Blumenau, v. 12, n.2, p.302-323, mai./ago. 2017 \\ DOI: http://dx.doi.org/10.7867/1809-0354.2017v12n2p302-323}

tiveram uma influência paulista na sua formação e/ou atuação educacional e foram impressas pela Editora Melhoramentos de São Paulo ${ }^{5}$.

A Coleção Proença é de autoria do professor Antonio Firmino de Proença, formado pela Escola Normal da Capital do Estado de São Paulo. Sua atuação educacional foi marcada por diversas relações com educadores e idealizadores das discussões que se colocavam sobre a Escola Nova, entre eles: Fernando de Azevedo, Amadeu Mendes, Sampaio Dória, Renato Jardim e Lourenço Filho (GAZOLI, 2011).

A Série Braga foi escrita por Erasmo Braga, natural de São Paulo, com uma formação marcada pelos missionários norte-americanos, na Escola Americana e no Colégio Protestante, em São Paulo, e participou da primeira turma do Instituto Teológico. Braga foi professor em instituições como o Colégio Progresso e o Colégio Mackenzie. De acordo com Massoti (2007), na escrita de seus livros, Braga "buscava a adequação de conteúdos aos objetivos e programas da escola renovada" (MASSOTTI, 2007, p. 76).

Pela formação e atuação educacional desses dois autores, é possível denotar que esses didáticos representavam uma referência do modelo educacional paulista, impregnada de elementos nacionalistas. Todavia, chama a atenção o fato de um colégio católico solicitar um livro de leitura, didático, de um autor com sólida formação protestante, tendo em vista que os livros de leitura eram impregnados de valores, de lições de moral, e de outros aspectos formativos que carregavam em si uma visão de mundo. Neste caso, sua adoção indicaria um aval nos temas ali abordados e o reconhecimento das estratégias pedagógicas empreendidas pelos protestantes em suas práticas de ensino e difusão da leitura. Conforme Bittencourt chama a atenção, os livros didáticos são

\footnotetext{
${ }^{5} \mathrm{Na}$ Melhoramentos de São Paulo, com a morte de Arnaldo de Oliveira Barreto, criador e coordenador da Biblioteca Infantil, a editora "[...] convidou, em 1926, o educador paulista Lourenço Filho. Ao lado de Oliveira Barreto, Carneiro Leão e Fernando de Azevedo, entre outros porta-vozes da renovação educacional que disputava espaço no país, Lourenço Filho já havia colaborado com a Revista Nacional, que a Melhoramentos lançara em 1921 e que conferiu aos assuntos de educação um lugar de destaque" (SOARES, 2010, p.160 ). Na editora, Lourenço Filho também dirigiu a Biblioteca de Educação, uma coleção direcionada aos professores, no período de 1927 até a década de 1970 e, por essa representação, proporcionou interlocuções entre os defensores da renovação educacional, representantes do movimento escolanovista, entre eles, o professorado principalmente paulista, autores de livros didáticos que circularam pelo Brasil todo.
} 


\section{Atos de Pesquisa em Educação - ISSN 1809-0354 \\ Blumenau, v. 12, n.2, p.302-323, mai./ago. 2017 \\ DOI: http://dx.doi.org/10.7867/1809-0354.2017v12n2p302-323}

[...] um depositário dos diversos conteúdos educacionais, suporte privilegiado para recuperar os conhecimentos e técnicas consideradas fundamentais por uma sociedade em determinada época. [...] E sem dúvidas, o livro didático é também um veículo portador de um sistema de valores, de uma ideologia, de uma cultura. (BITTENCOURT, 2008, p. 14)

Os livros solicitados foram publicados pela Companhia Melhoramentos de São Paulo. A partir de 1927, Lourenço Filho criou a Biblioteca de Educação da Companhia Melhoramentos, um projeto editorial expressivo e de referência para o campo educacional ${ }^{6}$.

No processo de expansão editorial, com a divulgação dos ideais dos renovadores educacionais, tendo como expoente na editora, Lourenço Filho, a Melhoramentos "preocupava-se em difundir autores e títulos envolvidos com as inovações em andamento, providenciando para tanto a incorporação de professores afamados", e seus exemplares cruzavam as fronteiras de São Paulo, chegando a muitos outros estados (MONARCHA, 2010, p. 53).

Os títulos e autores da Editora Melhoramentos, solicitados pelas Irmãs Passionistas, traziam traços de uma opção intelectual que compactuava com a nova pedagogia.

Há aí pistas que permitem inferir algumas hipóteses sobre a escolha desses livros para o Colégio Santo Antonio pelas Irmãs. Primeiro, destaca-se a inspiração na referência no modelo educacional paulista; segundo, o trânsito fluido da figura de Lourenço Filho entre os educadores dos diferentes grupos, dos pioneiros e dos católicos; no caso da Coleção Proença, o fato desses livros, apesar de não fazerem parte da Biblioteca de Educação, carrega o selo da Editora Melhoramentos e da figura do Lourenço Filho, por extensão ${ }^{7}$; e, no caso da Série Braga, a hipótese mais plausível é a de que as Irmãs tenham tido contato com esse livro em seu período de

\footnotetext{
${ }^{6}$ Tal projeto fazia parte de um conjunto de estratégias para difundir a pedagogia da Escola Nova pelo impresso e foi desenvolvida por outros intelectuais do grupo em lugares distintos. Nesse aspecto é digno de nota o projeto editorial encampado por Fernando de Azevedo na Companhia Editora Nacional com a Biblioteca Pedagógica Brasileira e as várias coleções que compreendia, com destaque para a Coleção Atualidades Pedagógicas, título bem sugestivo da intencionalidade do projeto.

Proença tinha uma ligação política com Lourenço Filho, quando este nomeou Antonio Firmino de Proença para o cargo de diretor da Escola Normal da Praça da República (DIARIO NACIONAL, 1930, p. 8), essa relação ia também para os aspectos pedagógicos, nas representações do Estado de São Paulo, como por exemplo, na $4^{\text {a }}$ Conferência Nacional de Educação (DIARIO NACIONAL, 1931, s.p.). Outra interação importante entre os dois professores, foi o fato de Proença ter publicado um livro pela Biblioteca de Educação, em 1929, intitulado "Como se ensina geografia".
} 


\section{Atos de Pesquisa em Educação - ISSN 1809-0354 \\ Blumenau, v. 12, n.2, p.302-323, mai./ago. 2017 \\ DOI: http://dx.doi.org/10.7867/1809-0354.2017v12n2p302-323}

formação/atuação profissional em São Paulo, além de também possuírem o selo "Lourenço Filho", que apesar de dirigir a Série apenas após a morte de Erasmo Braga, na década de 1930, os mesmos já eram utilizados em sua gestão no período como reformador no Ceará, em 1922 (A LUCTA, 1922, p. 1).

Sobre a Coleção Proença, em uma exposição na Cia. Melhoramentos de S. Paulo, em 1928, o jornal Correio Paulistano comentou sobre tal evento e fez uma descrição sobre o que seria a Coleção:

Collecção de livros para o ensino primario, desde a Cartilha até o 3.0 livro de leitura, de autoria do inspector escolar Antonio Firmino de Proença. Já se acha adoptada nos Estados de São Paulo e Pernambuco. As suas liccções estão muito bem graduadas, optimamente ilustradas, [...] versando sobre assumptos attrahentes, sugestivos e uteis. (CORREIO PAULISTANO, 1928, p. 9)

Os dois livros da Coleção Proença solicitados pelas Irmãs foram lançados em torno da década de 1920. A primeira edição do $1^{\circ}$ livro de leitura é do ano de 1926 , e do $3^{\circ}$, é de $1928^{8}$.

Sobre a divisão temática, o $1^{\circ}$ livro da Coleção Proença trouxe 52 lições e em quase metade, ou seja, 25 lições trataram de temas que envolviam o ensino de ciências, valorizando a cientificidade e observação do meio, hábitos comportamentais, como atitudes de trabalho e cuidados com a higiene, temas históricos, assuntos regionais e a defesa do nacionalismo (PROENÇA, [s.d.]a).

No $3^{\circ}$ livro da Coleção Proença, o autor manteve o mesmo estilo na produção dos textos e nos assuntos tratados, por meio das 75 lições, cerca de $70 \%$ dos conteúdos abordados, giraram em torno da disciplina de ciências, hábitos de higiene e de trabalho, obediência às leis, nacionalismo e história, exaltando alguns nomes brasileiros (PROENÇA, [s.d.]b). Conforme situa Carvalho (1989, p. 10), era isso que se visava implantar, por meio da educação, no período republicano: a regeneração do brasileiro a partir de um "núcleo da nacionalidade, tornando-as saudáveis, disciplinadas e produtivas, eis o que se esperava da educação, erigida nesse imaginário em causa cívica de redenção nacional".

\footnotetext{
${ }^{8}$ Para esta análise, as edições utilizadas dos livros da coleção Proença foram a $37^{\mathrm{a}}$ do $1^{\circ}$ livro de leitura, o qual não traz o ano de publicação, e com a $15^{\mathrm{a}}$ do $3^{\circ}$ livro de leitura, também sem data de publicação.
} 


\title{
Atos de Pesquisa em Educação - ISSN 1809-0354 \\ Blumenau, v. 12, n.2, p.302-323, mai./ago. 2017 \\ DOI: http://dx.doi.org/10.7867/1809-0354.2017v12n2p302-323
}

De forma semelhante, a Série Braga apresentava o mesmo ideal da Coleção Proença, trabalhando com textos e narrativas, que traziam conhecimentos científicos, voltados principalmente para a história, regionalismo e nacionalismo.

A $1^{\text {a }}$ edição do livro Leitura II, solicitado por Irmã Faustina, foi lançada em $1919^{9}$. No lançamento desse livro, o jornal Correio Paulistano, publicou a seguinte nota, no dia 8 de janeiro de 1920:

\begin{abstract}
Está em circulação este segundo livro de leituras, da série Braga, trabalho gráfico irreprehensivel que sobremaneira honra os prélos nacionaes, da casa paulista Weiszflog Irmãos. O seu autor, o ilustre intelectual o professor sr. Erasmo Braga, [...] ha muito feito nas letras do paiz, foi grandemente feliz na sua organização. (CORREIO PAULISTANO, 1920, s.p.)
\end{abstract}

Percebe-se a colocação de Erasmo Braga, como um autor de livros didáticos e intelectual, na nova fase educacional que estava em voga. $O$ jornal descreveu o livro como:

[...] este novo livro de leituras, [...] organizado, de acordo com os methodos mais preconizados pelos educadores modernos, nada deixa a desejar: attrai, [...] ministra e desenvolve conhecimentos de cousas e historia, adapta-se admiravelmente á psychologia dos jovens leitores, é estimulo, é moral, recrea e educa. (CORREIO PAULISTANO, 1920, s.p.)

Seguindo a mesma linha na divisão temática dos outros livros de leitura que foram solicitados ao Colégio, da Coleção Proença, no Livro II da Série Braga, das 84 lições, $75 \%$ versaram sobre assuntos científicos, hábitos comportamentais e de trabalho, regionalismo, história e nacionalismo (BRAGA, [s.d.]).

Pelos livros adotados e na análise dos assuntos abordados, percebe-se que as referências basilares que circularam no Colégio Santo Antonio, tinham como unidade a defesa de um ensino renovador ancorado em princípios formativos relacionados ao nacionalismo, higiene, trabalho e obediência. Seus autores, em maior ou menor escala, aproximaram-se de figuras expressivas do movimento da Escola Nova, no Brasil. Assim, é possível depreender uma possível aproximação das referências que embasaram o movimento educacional e os debates que

\footnotetext{
${ }^{9}$ Para este trabalho, analisou-se a $86^{a}$ edição. Não consta o ano de publicação da mesma, porém, em uma assinatura na folha de rosto do livro, tem-se datado o ano de 1937.
} 


\section{Atos de Pesquisa em Educação - ISSN 1809-0354 \\ Blumenau, v. 12, n.2, p.302-323, mai./ago. 2017 \\ DOI: http://dx.doi.org/10.7867/1809-0354.2017v12n2p302-323}

contribuíram para configurar e modelar a escola paulista com o Colégio Santo Antonio, em Colombo.

Em relação à utilização de outros materiais, não se tem a menção, nem mesmo nos impressos sobre o uso destes no trabalho das lições, para que a criança tivesse contato com o concreto. Em alguns textos, sugere-se a observação do meio, mas não é possível inferir o modo como estes foram trabalhados em sala e se tinham como base as questões sensitivas do ensino intuitivo.

Sobre o uso dos materiais didáticos, pelas Irmãs Passionistas, não se encontrou indícios de outros livros didáticos, como os de Matemática. Talvez, isso tenha relação com "as mudanças nos programas da escola elementar", que no período republicano "eram sustentadas por propostas que conferiam ao livro de leitura proeminência sobre os demais" (BITTENCOURT, 2008, p. 48). Inclusive, conforme aponta Bittencourt (2008, p. 48), a Comissão que revia as obras utilizadas pelas escolas públicas de São Paulo, em 1908, "chegou a recomendar que os alunos utilizassem somente os livros de leitura. Para as demais disciplinas bastariam as explicações do mestre".

Nesse sentido, retomando uma crítica feita pelo professor Proença, no prefácio do $3^{\circ}$ livro de leitura, em que comenta o fato das escolas não utilizarem outros materiais didáticos, cabia a esses livros de leitura o necessário trabalho literário, mas que também contemplasse questões de conhecimentos gerais, já que: "Como obra da instrucção ha de conter assumptos de historia da patria, de geographia, de hygiene, etc. Pelo lado educativo não pode deixar de ser obra literaria" (PROENÇA. [s.d.]b, p. IV).

Desta forma, fazendo os saberes elementares da Matemática parte dos programas de ensino, e consequentemente devendo compor as aulas, tem-se antagonicamente um cenário em que muitas instituições não utilizavam materiais específicos para o ensino dos mesmos, cabendo aos livros de leitura o trabalho destes conteúdos. Com isso, encontraram-se de modo não muito expressivo, além dos temas já destacados anteriormente, lições nos livros de leitura que trabalharam com saberes da Aritmética e da Geometria, tanto na Coleção Proença quanto na Série Braga. 


\section{Atos de Pesquisa em Educação - ISSN 1809-0354 \\ Blumenau, v. 12, n.2, p.302-323, mai./ago. 2017 \\ DOI: http://dx.doi.org/10.7867/1809-0354.2017v12n2p302-323}

No $1^{\circ}$ livro de leitura do professor Antonio Firmino de Proença, se tem a lição intitulada "O endez", em que é construída a noção de quantidade de uma dúzia, através da produção de ovos de uma galinha de Rui, personagem principal da história. Também se destacam na narrativa outras operações matemáticas, como a construção da tabuada a partir da soma de parcelas iguais. Tais operações foram construídas no texto, já que da dúzia inicial produzida pela galinha de Rui,

[...] haviam de nascer doze pintos. Destas, seis seriam frangas; os outros, frangos. Os frangos iriam para a panella, as frangas ficariam para gallinhas. As galinhas poriam doze ovos cada uma. Dos ovos nasceriam setenta e dois pintos, dos quaes trinta e seis dariam frangas... Era o que o Rui pensava, antevendo a enorme criação. (PROENÇA, [s.d.]a, p. 87)

Porém, esse saber aritmético não ficou desarticulado das propostas educacionais do período, pois Rui "calculava os lucros que iria ter com a venda dos ovos e das frangas" (PROENÇA, [s.d.]a, p. 87). Essas propostas tinham por objetivo formar um cidadão para o trabalho, ensinando-o a usar o dinheiro dentro de uma concepção capitalista de sociedade, tendo como cenário uma possível realidade da criança, em um Brasil marcadamente rural.

Essa aplicabilidade entre os conteúdos ensinados e a formação do cidadão, demonstra que a "escola primária brasileira, desde sua organização em forma seriada cultuou em sua programação o espírito prático, saberes úteis para a vida. Seria essa a finalidade da Aritmética, matéria sempre presente na organização curricular da escola primária" (PINTO; PORTELA, 2015, p. 60).

Especificamente na sociedade paranaense, diversas mudanças aconteceram nas propostas de ensino, a partir da década de 1920, impulsionadas por Cesar Prieto Martinez. Dentre essas ações,

[...] voltadas ao ensino da Aritmética, destacam-se aspectos do "espírito prático" dos saberes aritméticos, veiculados pelo programa da escola primária do Paraná, de 1921, anteriormente também discutido em conjunto com demais programas de Aritmética relativos ao período compreendido entre 1901 e 1963. (PINTO; PORTELA, 2015, p. 62)

Nesse saber aplicado e revigorando as discussões de uma educação nova no Brasil, figuras como Lourenço Filho e Fernando de Azevedo foram importantes na 


\section{Atos de Pesquisa em Educação - ISSN 1809-0354 \\ Blumenau, v. 12, n.2, p.302-323, mai./ago. 2017 \\ DOI: http://dx.doi.org/10.7867/1809-0354.2017v12n2p302-323}

introdução de práticas ditas renovadas e suas discussões a respeito da escola primária. Sobre

Os saberes elementares para os primeiros anos escolares, no discurso de Fernando Azevedo, [...] buscam a serventia para a vida cotidiana dos egressos. Não se confundem com os elementos de uma ciência ou ciências. Os primeiros passos na matemática configuram-se também como terminais, "visam o ensino da Aritmética e da Geometria, [...] decorra da vida prática e a ela se prenda". (VALENTE, 2015, p. 12)

Ou seja, destaca-se a aplicação prática dos saberes elementares, como a Aritmética e a Geometria. Sobre a Geometria, encontrou-se uma lição no livro Leitura II, do professor Erasmo Braga, com o título "Uma curva difícil", em que são demonstrados dois modos para se construir uma elipse, que José, personagem da história, precisava desenhar, para o bordado de sua mãe, evidenciando uma articulação da Matemática aplicada aos trabalhos domésticos. Os modos descritos no livro foram:

\footnotetext{
A figura, que desejas riscar para o bordado de mamãi, é mais facil de fazer que suppões. Si tu queres uma elipse pouco diferente da circunferencia, pouco excentrica, toma o rolo de fazer pasteis, põe-lhe em cima um pedaço de papel e, desenhando uma circunferencia com o compasso, obténs uma ellipse. (BRAGA, [s.d.], p. 30)
}

A outra forma de desenhar uma elipse é descrita da seguinte maneira: "Si, porem, queres uma ellipse alongada, de maior excentricidade, finca sobre o papel estendido na mesa dois alfinetes, e com uma linha sem fim, atada em laço, passada fora dos alfinetes, e um lapis, obterás a figura assim..." (BRAGA, [s.d.], p. 30).

Ambos os modos foram demonstrados através de ilustrações, colocando esse saber elementar da Geometria, na construção de uma elipse, uma utilidade prática para o cotidiano, por meio de um trabalho doméstico, da mãe de José.

Por meio dessas lições, que tinham em voga os saberes elementares da Matemática, mesmo não aparecendo de forma expressiva nos livros analisados, demonstra-se a articulação dela com as demais atividades propostas por esses materiais, com forte sentido pragmático e voltadas para o desenvolvimento de hábitos e valores relacionados ao trabalho. 


\section{Atos de Pesquisa em Educação - ISSN 1809-0354 \\ Blumenau, v. 12, n.2, p.302-323, mai./ago. 2017 \\ DOI: http://dx.doi.org/10.7867/1809-0354.2017v12n2p302-323}

\section{CONCLUSÃO}

No bojo das discussões e embates entre Estado e Igreja, com o advento republicano e sua acentuação nas décadas de 1920 e 1930, pode-se denotar que as mesmas giraram em torno do plano político, em que um lado defendia um Estado laico e o outro colocava a construção de uma nação a partir de um Brasil católico. Dentre as estratégias utilizadas por estes dois grupos para consolidação desses ideais, algumas foram direcionadas para o campo educacional. Porém, mesmo estando em polos distintos, as discussões sobre uma renovação educacional brasileira encontraram convergências em muitos aspectos entres "renovadores e católicos", trazendo rudimentos de um ensino intuitivo. Se não foi possível identificar a questão dos usos dos materiais e o modo sensitivo do concreto, pode-se ao menos observar uma influência que coloca em pauta a formação do cidadão republicano, ideais defendidos desde o Ensino Intuitivo que continuam com a Escola Nova.

Pode-se exemplificar essa aproximação, por meio das Irmãs Passionistas, na coordenação do Colégio Santo Antonio, uma escola confessional católica, no município de Colombo, entre os anos de 1927 e 1933. Dentre essas aproximações, destaca-se a origem paulista das freiras Passionistas, possibilitando que elas tivessem uma formação tanto acadêmica quanto religiosa, no convento que estava situado em São Paulo, trazendo para a escola católica de Colombo, elementos de uma educação paulista.

No plano pedagógico, compreendem-se os livros de leitura como um depositário de conteúdos e veículo portador de um sistema de valores, em que os solicitados pelas Passionistas, defendiam muitos dos ideais para a construção de uma pátria, pautados no nacionalismo, ordenamento dos hábitos comportamentais e de trabalho, além dos conteúdos científicos. Tais tópicos se fizeram presentes em grande parte dos assuntos destes materiais, inclusive nas lições que envolveram os saberes elementares da Matemática e que estavam articuladas com as discussões educacionais do período, trazendo um ensino prático, eficaz e com aplicabilidade no cotidiano dos alunos; objetivos defendidos, por exemplo, por Cesar Prieto Martinez, no Paraná, e Fernando de Azevedo. 


\section{Atos de Pesquisa em Educação - ISSN 1809-0354 \\ Blumenau, v. 12, n.2, p.302-323, mai./ago. 2017 \\ DOI: http://dx.doi.org/10.7867/1809-0354.2017v12n2p302-323}

Como a escrita de um impresso jamais é neutra encontrou-se, nos professores Antonio Firmino de Proença e Erasmo Braga, em conjunto com a Editora Melhoramentos de São Paulo, uma aproximação com intelectuais do período que defendiam mudanças educacionais de uma escola renovada, posta em discussão e visando às mudanças desde o início da República. Nesses indícios, e por São Paulo ser um dos estados porta-voz da renovação educacional, pode-se apreender um entrelaçamento de uma instituição católica paranaense com o ensino renovador paulista.

\section{EVELYN ORLANDO}

Doutora em Educação pela UERJ. Professora da Pontifícia Universidade Católica do Paraná - PUCPR.

\section{MARA MOTIN}

Mestre em Educação pela PUCPR. Professora da Pontifícia Universidade Católica do Paraná - PUCPR.

\section{REFERÊNCIAS}

ALVES, M. Sistema católico de educação e ensino no brasil: uma nova perspectiva organizacional e de gestão educacional. Revista Diálogo Educacional, Curitiba, v. 5, n.16, p. 209-228, set./dez. 2005.

BITTENCOURT, C. Livro didático e saber escolar (1810 - 1910). Belo Horizonte: Autêntica Editora, 2008.

CARVALHO, M. M. C. A escola e a República. 1 ed. São Paulo: Editora Brasiliense, 1989.

CARVALHO, M. M. C. Modernidade pedagógica e modelos de formação docente. São Paulo em Perspectiva, São Paulo, v. 14, n. 1, p. 111 - 120, 2000.

CARVALHO, M. M. C. Reformas da Instrução Pública. In. LOPES, E. M. T.; FARIA FILHO, L. M.; VEIGA, C. G. (orgs.). 500 anos de Educação no Brasil. Belo Horizonte: Autêntica, 2011. p. 225-251.

GAZOLI, M. R. Série de leitura Proença (1926 - 1928) e o ensino da leitura no Estado de São Paulo. São Paulo: Cultura Acadêmica, 2011.

GINZBURG, C. Mitos, emblemas, sinais: morfologia e história. Tradução Federico Carotti. - São Paulo: Companhia das Letras, 1989. 


\section{Atos de Pesquisa em Educação - ISSN 1809-0354 \\ Blumenau, v. 12, n.2, p.302-323, mai./ago. 2017 \\ DOI: http://dx.doi.org/10.7867/1809-0354.2017v12n2p302-323}

MAGALDI, A. M. B. M. Lições de Casa: discurso pedagógico destinados a família no Brasil. Belo Horizonte, MG: Argvmentvm, 2007.

MASCHIO, E. C. F. A escolarização dos imigrantes e de seus descendentes nas colônias italianas de Curitiba, entre táticas e estratégias de italianità e brasilitá (1875-1930). 2012. 340 f. Tese (doutorado) - Programa de Pós-Graduação em Educação. Universidade Federal do Paraná, Curitiba, 2012.

MASSOTTI, R. A. Erasmo Braga e os valores protestantes na educação brasileira. 2007. 182 f. Dissertação (mestrado) - Mestrado em Ciências da Religião.

Universidade Presbiteriana Mackenzie, São Paulo, 2007.

MONARCHA, C. Lourenço Filho. Recife: Fundação Joaquim Nabuco, Editora Massangana, 2010.

NAGLE, J. Educação e sociedade na Primeira República. São Paulo: EPU, 1974.

ORLANDO, E. A. Por uma civilização cristã: a coleção Monsenhor Álvaro Negromonte e a pedagogia do catecismo (1937 - 1965). 2008. 313p. Dissertação (mestrado) - Mestrado em Educação. Universidade Federal de Sergipe, São Cristóvão.

PINTO, N. B.; PORTELA, M. S. Em busca do sentido (prático) da Aritmética dos primeiros anos escolares: Cartas de Parker no ensino primário. In: VALENTE, W. R. (org). Cadernos de trabalho. São Paulo: Editora Livraria Física, 2015. Volume 5, p. $55-88$.

RESENDE, F. M.; SOUZA, R. C. O método intuitivo e a Escola Nova: Discussões educacionais em fins do século XIX e início do século XX. In: Congresso de Pesquisa e Ensino em História da Educação, III, 2005, Minas Gerais. Anais. Minas Gerais: Congresso, 2005, p. $1-11$.

SANTOS, I. S. F.; PRESTES, R. I.; VALE, A. M. Brasil, 1930 - 1961: Escola Nova, Ldb e disputa entre escola pública e escola privada. Revista HISTEDBR On-line, Campinas, n.22, p.131-149, jun. 2006.

SOARES, G. P. Os Irmãos Weiszflog em busca dos mercados escolares: identidades das edições Melhoramentos dos primórdios à década de 1960. In: BRAGANÇA, A.; ABREU, M. (orgs). Impresso no Brasil: Dois séculos de livros brasileiros. São Paulo: Editora Unesp, 2010. cap. 8; 157-169.

SOUZA, R. F. Templos de civilização: a implantação da escola primária graduada no Estado de São Paulo: (1890 - 1910). São Paulo: Fundação Editora da UNESP, 1998.

TANURI, L. M. História da formação de professores. Revista Brasileira de Educação, n. 14, mai/jun/jul/ago, 2000, p. 61-88. 


\section{Atos de Pesquisa em Educação - ISSN 1809-0354 \\ Blumenau, v. 12, n.2, p.302-323, mai./ago. 2017 \\ DOI: http://dx.doi.org/10.7867/1809-0354.2017v12n2p302-323}

TOLEDO, M. R. A. Coleção Atualidades Pedagógicas: do projeto político ao projeto editorial (1931 - 1981). 2001. 295 f. Tese (doutorado) - Doutorado em Educação. Pontifícia Universidade Católica de São Paulo, São Paulo, 2001.

VALENTE, W. R. Subsídios para história dos saberes elementares matemáticos: Caetano de Campos (1891), Fernando de Azevedo (1930). In: Seminário Temático, XII, 2015, Curitiba. Anais. Paraná: Seminário Temático, 2015, p. 175 - 187.

ZOCA, V. E. A contribuição do Colégio Santo Antonio para o processo de romanização da Igreja Católica e para a manutenção da cultura italiana. 2007, 175 p. Dissertação (mestrado) - Mestrado em Educação. Pontifícia Universidade Católica do Paraná, Curitiba.

\section{FONTES}

A LUCTA. O Ensino. 1922, 29 de julho, p. 1.

BRAGA, E. Leitura II. 86 ed. São Paulo: Companhia Melhoramentos de São Paulo (Weiszflog Irmãos Incorporada), [s.d.], 241 p.

CORREIO PAULISTANO. Bibliographia. 1920, São Paulo, 08 de janeiro.

CORREIO PAULISTANO. Na Cia. De Melhoramentos de São Paulo. Correio Paulistano. 1928, São Paulo, 08 de dezembro, p. 9.

DIARIO DO PARANÁ. Religiosa é a primeira a usufruir tratado de igualdade. 1972, Curitiba, ${ }^{\circ} 5041$, ano XVIII, 28 de abril.

DIARIO NACIONAL. Escola Normal. 1930, São Paulo, 13 de dezembro, p. 8.

DIARIO NACIONAL. O ensino em S. Paulo. 1931, São Paulo, 11 de dezembro.

LIVRO TOMBO, número II. Acervo da Paróquia Nossa Senhora do Rosário, 1900.

O ESTADO DE SÃO PAULO. À Caridade em S. Paulo - O que são e como vivem os Asylos - Uma visita ao abrigo de Santa Maria (notas de um repórter). 1920, São Paulo, 05 de julho, p. 5.

PARANÁ. Departamento Estadual de Arquivo Público. Mapas Escolares. 1926.

PARANÁ. Relatório da Secretaria dos Negócios do Interior, Justiça e Instrução Pública, 1928.

PARANÁ. Relatório da Secretaria dos Negócios do Interior, Justiça e Instrução Pública, 1929.

PARANÁ. Relatório da Secretaria dos Negócios do Interior, Justiça e Instrução Pública, 1930a. 
PARANÁ. Departamento Estadual de Arquivo Público. Ofício. Livro 2311, 1930b.

PARANÁ. Relatório da Secretaria dos Negócios do Interior, Justiça e Instrução Pública, 1931.

PASSIONISTAS. Elenco das Religiosas. Acervo da Província São Gabriel da Virgem Dolorosa, 1920.

PASSIONISTAS. Histórico da casa. 1951.

PASSIONISTAS. Subsídios para a história da província São Gabriel da Virgem Dolorosa. São Paulo, [s.d.].

PROENÇA, A. F. $1^{\circ}$ livro de leitura. 37 ed. São Paulo: Companhia Melhoramentos de São Paulo (Weiszflog Irmãos Incorporada), [s.d.]a, 160 p.

PROENÇA, A. F. $3^{\circ}$ livro de leitura. 15 ed. São Paulo: Companhia Melhoramentos de São Paulo (Weiszflog Irmãos Incorporada), [s.d.]b, 236 p. 